\title{
Research on Vocational English Reading Teaching
}

\author{
Simin Liu \\ Changjiang Institute of Technology, Wuhan Hubei, 430212, China
}

\begin{abstract}
Keywords: Vocational English, Reading Teaching, Research and Application
\end{abstract}
\begin{abstract}
With the continuous improvement of the economic development level of our country, the reform of trait-oriented education also is continuously deepened. Vocational English is an important course in vocational education, and an important channel and approach to improve the comprehensive quality of vocational technique talents and widely popularize English. In order to facilitate vocational English teaching, and arouse students' learning interest, continuous reform in teaching method should be carried out to enhance the application and research of English reading in English teaching. In this article, research on the method and strategy of vocational English reading teaching will be made, with a view to reflecting the importance of vocational English reading teaching and improve the effect of reading teaching.
\end{abstract}

\section{Introduction}

Presently, the methods of reading teaching just include explaining and traditional cramming method in vocational English teaching. Teachers tend to make little account of students' learning process. Most English teachers focus on the method of finding out answers to questions in reading teaching only, and just emphasize reading exercises; while they never researched reading strategy and reading method deeply and thoroughly. Thus, students have little interest in reading. In modern English teaching, English reading teaching can help students to improve their English-speaking ability and English application ability, becoming an important means of cultivating English talents and improving student's comprehensive accomplishments.

\section{Key Factors Influencing Classroom English Reading Strategy}

\section{Language Knowledge}

English is a language. Learning English is a process of mastering a language, which is a time-consuming process. Both aptitude and strategy are important in language learning, by which twice as much can be accomplished with half the effort. Language knowledge includes phonology, vocabulary, grammar, etc. Phonology, vocabulary and grammar are the fundamental elements of language knowledge. Any one who want to understand or comprehend English writings roughly should have a good command of language knowledge. Generally speaking, the more solid the language foundation is, the easier you read articles. Otherwise, those who master little vocabularies or know vocabularies vaguely, or is just able to pronounce or spell out words, or know little about grammatical rules usually read slowly, because these factors are likely to cause spelling mistakes, misunderstanding or difficulties in understanding. The background knowledge also matters a lot, which is important for guessing the meaning of obscure words or sentences based on the analysis of the overall context or text structure.

\section{Background Knowledge}

Reading comprehension is an important way for writers to communicate with readers. In order to effectively and accurately communicate with writers, readers should master certain background knowledge and do a large amount of reading. Background knowledge, helpful for reading, is divided into two types, namely cultural background knowledge and subject culture knowledge. Language is the carrier and platform of culture. In addition to language knowledge, students also should master related cultural background knowledge, so as to understand articles better. Take the example of the 
article of New Year Traditions all around the World. Students should read through and understand the article, and know something about the cultures of the ancient Egypt, the ancient Babylon, and other countries concerned. In this article, the traditions of new year festival of countries and regions around the world have been introduced, covering the origin of new year festival and different manners and customs of countries in new year festival. If students know nothing about the related cultural background knowledge, they will not fully understand the article, let alone the obscure words or sentences. Thus, knowing the background knowledge of an article well is critical to reading. English reading involves much contents, and covers a lot of things, which requires students to know something about related subjects. Take the example of the article of Why Do We Believe That the Earth Is Round. The writer put forward some arguments to disprove the viewpoints of the opposite side. In this article, playing bridge is mentioned frequently. Thus, students are required to know bridge well. The article of Helicopter is another example. Students should know the performances, features and usage of airplane well, read quickly, and accurately understand the words. Otherwise, reading this article will become difficult[1].

\section{Text Structure Knowledge}

Usually, students will have the following problems in reading: obscure words, inaccurate analysis of sentence structure, and incomprehension of main idea of an article. Looking up the dictionary or other materials to understand the obscure words is often a time-consuming effort, which even will be in vain. Besides, if you cannot comprehend a sentence, the context also will be hard to understand. To solve this problem, you should comprehend the main idea of an article first. An article is not constructed just by words stuffing, but based on the certain logical thinking throughout the main idea[2]. Therefore, text structure knowledge matters a lot in reading. An article can be analyzed from the macrostructure and the microstructure. There are three thinking modes of discourse. The first one is general-particular mode, of which the specific practice is to make a brief summary first, and provide an example and make a detailed description based thereon; or detail mode, namely generalize and summarize the overall contents first, and then present the details. Here is an example. "One hundred years ago, school teachers were expected to provide a variety of services in addition to their teaching duties and to behave themselves in an exemplary manner. (1) They cared for the oil lamps, tended the fire. (2) Women, teachers could not marry." Sentence (1) is a summary of the overall article, while sentence (2) is an illustrative example. This article is a general-particular article. The second one is contrast-match mode, namely contrast the differences among several groups of things, to form a complete discourse in combination with the general-particular mode. The last one is problem-solution mode, namely make a situation-reaction-evaluation combination[3].

\section{Reading Method}

Linguistic sign is an important factor influencing reading efficiency, which will affect reading speed and the degree of article understanding. At the beginning of English learning, many students tend to be immersed in some information related to semanteme or syntax, and start mechanical reading or exercises, but make little account of word distinguishment and analysis. Those whose learning ability is strong would handle with the key words or key sentences first, and then make distinguishment and analysis. Besides, these students will spend much time on reading. Thus, they can greatly reduce errors and interruptions, and raise reading efficiency. Generally, the students with a strong learning ability have solid language background knowledge, are capable of fully understand text structure, and can select proper reading methods according to the type of reading materials.

\section{Discussions on Implementation of English Reading Teaching Strategy}

\section{Select A Good Reading Teaching Mode}

Generally, there are two modes of reading pattern, i.e. bottom-up reading mode, and top-down reading mode. The bottom-top mode refers to starting from word spelling, letters, phrases, and sentence recognition, and focusing on simple word spelling to get some information at final. Readers 
are required to understand the meaning of each word and sentence to understand the overall article, and figure out the main idea of the article. On the contrary, the top-down mode refers to understanding the gist of paragraphs or the background of article first, and then learn the details by sentences and words. It is a scientific learning method to combine the two modes above, with which the nature of reading can be reflected, students' reading ability can be trained, and students' interest in reading can be raised[4].

\section{Comprehensively apply the method of reading teaching}

The key to effective reading is to integrate capabilities at different levels. Teachers should train students' reading capability, which is very important. Without a proper reading strategy, it will be difficult to fulfill the reading task within the required time. The common reading strategies include skimming, scanning, prediction reading, guessing, etc. Skimming refers to fast reading, of which the aim is to comprehend the general idea of an article. At the stage of skimming, students don't have to peruse the overall article, but can adopt skip reading. Scanning is another method of fast reading, which is more demanding in precision and speed than skimming. Predication is not to passively accept or understand information, but to verify the predication and correct on this basis. In other words, it is to predict words with grammar, culture and the logic as the clue and in combination with the theme, topic and structure of article. Guessing refers to guessing or inferring the meaning of obscure words based on the understanding of the general idea of the article.

\section{English Reading Teaching Strategy}

There are many English reading strategies in wide use, which involve extensive contents, including special lecture, cognitive modeling, participation and guidance, observation and imitation, experience exchange, problem solving, cooperation, etc. In the use of each teaching method, the mobilization of student's enthusiasm, initiative and creativity should be emphasized, to truly implement the teaching strategies.

\section{Requirements for Teachers and Students in English Reading}

Reading comprehension is not a process that students passively accept and digest information, but a process that students and teacher interact, communicate and exchange with each other. The success of exchange is decided by language knowledge, background knowledge and reading strategy. Student's language knowledge, basic knowledge and proficiency in reading have positive correlation with their reading efficiency. These factors mutually affect each other, and support structural analysis and background knowledge. Selecting reading strategy according to the type of reading materials and reading purpose will make for reading efficiency. Teachers should consciously train the reading habit of students, guiding students to get rid of the habit of interpreting word by word and sentence by sentence before reading, helping students to form a habit of underlining or circling the unapprehended word or sentence, training students to form a habit of inferring information of article, to enhance the sense of careful thinking, and teaching students to decompose difficult sentences of complicated structure to exercise and read, and get important information from the context. In a word, analyzing sentence elements and figuring out sentence meaning are the most important means of reading. Students and teachers should properly select and use them.

\section{Classroom Reading Teaching Practice}

Training of teaching practice include the following steps. Step I Training of meta-knowledge. Introduce the importance of knowledge in independent study to students, strengthen the reading target of the subject in knowledge training, make writing records in each stage, and learn about the importance of metacognitive knowledge and metacognitive strategy. Step II Training of metacognitive strategy. In-class training mainly involves reading practice and reading effect. In experiment, in-class training refers to three aspects by the content of cognitive strategy and training guidance, namely process monitoring, plan formulation and evaluation. Set a goal first, and make a plan on this basis. Plan formulation involves selection of reading materials, time arrangement, application of strategy, and solutions to difficulties, etc[5]. Step III Carry out reading activities 
according to the content of each plan. Monitor reading. Guide students to monitor reading according to the reading task and purpose, such as extensive reading or intensive reading, or consciously monitor self-reading, such as thinking while reading or recording while reading, guessing meaning of words or gist of paragraphs based on the context, underlining key words or sentences, and learning to generalize or summarize the main idea of article. Step IV Self-questioning. Check the answers or the experiment results, and handle the problems promptly, if any. Evaluate the reading plan and reading strategy of students by stage after finishing reading, and sum up the experience and learn lessons from the problems and errors, to prepare the next reading stage. Besides, draw up a plan of independent reading after class based on self-evaluation. Students are required to know about the extracurricular reading information and requirements, so as to carry out extracurricular reading better according to the plan; to record the feeling of extracurricular reading, the knowledge and information got from extracurricular reading, applied strategy, problems, and solutions; to be immersed in self-reading and adjust self-evaluation. Teachers are suggested to ask students to submit an extracurricular reading feeling report a week, inspect students' records, make comments thereon, and communicate with students. After the final exam, teachers can organize various activities for students, for mutual learning, mutual exchange, and mutual improvement. Through the application of the abovementioned reading strategies, it is found that applying the metacognitive strategy in English reading can not only improve the reading effect of students, but also promote and enhance the training of reading of students. In the promotion of trait-oriented education, changing students' learning beliefs and teachers' teaching concept will be favorable for the training of reading capability of students, and truly training students to form a habit of independent learning and independent thinking.

\section{Conclusion}

This article has mainly analyzed the influencing factors of vocational English reading teaching and the application of related strategies, and explained the importance of the background knowledge, basic knowledge and strategy application involved in English reading teaching. In order to facilitate vocational English reading, and improve the efficiency and accuracy of English reading, teachers are required to be good at using proper reading strategy and method, so as to promote the process of trait-oriented education reform of vocational school, and train talents with strong comprehensive capability for all the fields.

\section{References}

[1] ZHANG Xiang. Application and Research of Visualization Interaction Based on Concept Map in English Reading Teaching. China Educational Technology, 2013(3): 106-110.

[2] ZHANG Xiao. Enlightenment of Diverse Characteristics of Postmodernism to Public English Reading Teaching of Postgraduate. Foreign Language and Literature (Journal of Sichuan International Studies University),2010(3):141-144.

[3] WANG Meiqing. Application and Research of Task-based Teaching Method in Vocational English Reading Teaching. English on Campus (the last ten-day period), 2014(7): 28-28.

[4] ZHANG Yining. Agreement of Perceptual Comprehension with Rational Analysis-Case Study of College English Reading Teaching Based on "ATE" Reading Pattern. Heilongjiang Gaojiao Yanjiu, 2010(9): 189-192.

[5] LI Bo. Application of Schema Theory in Business English Reading Teaching-Example of Business English Reading Teaching.Jiaoyu Tansuo, 2012(2): 45-46. 